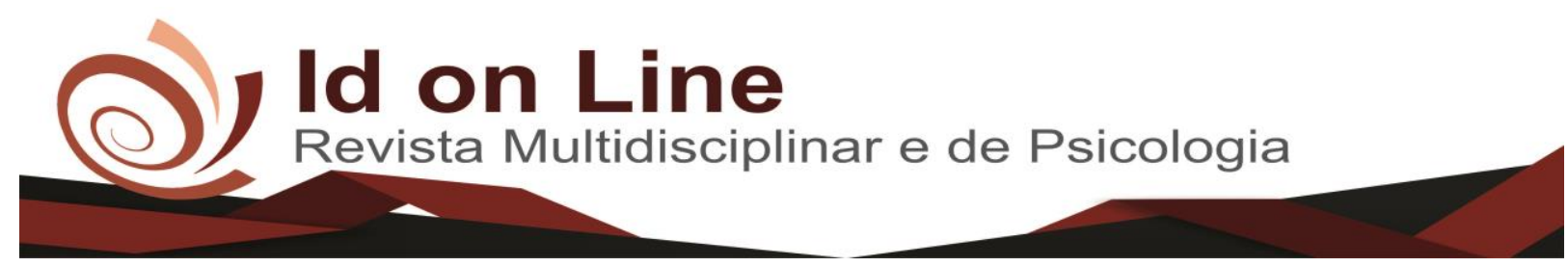

Artigo

\title{
Análise de Viabilidade da Implantação de uma Choperia na Cidade de Brejo Santo-CE
}

Áquila Takira Lima de Sousa ${ }^{1}$; Luan Henrique dos Santos ${ }^{2}$; Tharsis Cidália de Sá Barreto Diaz Alencar ${ }^{3}$

Resumo: A presente pesquisa refere-se ao estudo da viabilidade da implantação de uma choperia na cidade de Brejo Santo-CE, aplicado a área do entretenimento, e focado na percepção da área que se pretende atuar, proporcionando analises e estratégias que venham tornar o plano seguro e eficaz, sendo assim, para elaboração do estudo foram realizadas pesquisas quali-quantitativa e de pesquisas de campo, coletando informações que venham acrescentar no processo de tomada de decisões. Entretanto os resultados coletados foram satisfatórios tanto com relação a aspectos financeiros como econômicos, tendo em vista que o ciclo de vida da organização é conceituado em longo prazo, todavia, com retorno em curto prazo.

Palavra-chave: Empreendedorismo. Entretenimento. Análise de viabilidade.

\section{Feasibility Analysis of the Implantation of a Chopper in the City of Brejo Santo, State of Ceará}

\begin{abstract}
The business plan refers to the feasibility study of the implantation of a beer garden in the city of Brejo Santo-CE, applied to the entertainment area, and focused on the perception of the area that is intended to act, providing analyzes and strategies that will make the plan safe In order to prepare the study, qualitative-quantitative research was carried out, as well as field research, collecting information that could be added to the decisionmaking process. However, the results were satisfactory both in financial and economic aspects. since the organization's life cycle is conceptualized in the long term, however, with short-term return.
\end{abstract}

Keyword: Entrepreneurship. Entertainment. Business Plan.

\section{Introdução}

Em meio à globalização e a evolução das tecnologias, o cenário do mercado de trabalho está passando por diversas modificações, onde eleva o nível de competitividade entre as organizações, então para se mantiverem sólidos, precisam estar praticando frequentemente o ato de inovar, sendo este, um elemento crucial. Com tudo, esta pesquisa consiste em ajudar o

\footnotetext{
${ }^{1}$ Graduanda do curso de Administração do Centro Universitário Doutor Leão Sampaio, takiraadm@ gmail.com;

${ }^{2}$ Graduando do curso de Administração do Centro Universitário Doutor Leão Sampaio, luanhenrique.lh8@gmail.com;

${ }^{3}$ Professora orientadora do Centro Universitário Doutor Leão Sampaio, tharsis@leaosampaio.edu.br.

242 Id on Line Rev. Mult. Psic. V.12, N. 42, Supl. 1, p. 242-254, 2018 - ISSN 1981-1179
Edição eletrônica em http://idonline.emnuvens.com.br/id
} 
empreendedor a obter uma nova ação de forma segura. Com o propósito de aumentar a efetividade do empreendimento e reduzir ao mínimo os níveis de riscos.

Mediante estes aspectos, foram identificados os objetivos específicos, em que buscouse estudar o cenário da cidade de Brejo Santo-CE, que será implementada uma choperia, observar a demanda para a adesão no negócio e verificar os indicadores de viabilidade, para que esta pesquisa teórica se torne um grande negócio na prática.

Com o crescimento da cidade do Brejo Santo CE, cresce também o número de jovens e adultos que buscam por entretenimento. A cidade possui, no seguimento de choperia apenas um estabelecimento, deixando evidente uma nova oportunidade de adesão, vale ressaltar que poucos são os empreendimentos que buscam novas formas de satisfazerem os seus clientes, na procura de qualidade e um atendimento personalizado, o que acontece na realidade é o oposto, deixando-se levar pela zona de conforto ou por ser muito burocrática, que se faz um ponto favorável para a choperia. Na atualidade os novos gestores devem se atentar bastante as novas formas de empreender, uma vez que, a globalização e essa nova era cercada pelo mercado competitivo, exige muito das empresas que querem se manter solidadas. Com isso, deverá ser feita análises que segue logo abaixo, com o intuito de concretizar se existe viabilidade para a instalação dessa choperia?

- Analisar a viabilidade da implantação de uma choperia.

- Estudar o mercado da cidade a ser implantada.

- Elaborar plano de marketing.

- Desenvolver um planejamento produtivo

- Desenvolver um plano financeiro.

Mediante o mercado local foi constatado poucas opções que seguem o mesmo segmento de choperia, entretanto este plano é visto como uma oportunidade para satisfazer o desejo e gosto dos consumidores. Com isso busca-se suprir as expectativas dos futuros clientes e elevar seu nível de satisfação.

Para a academia, a presente pesquisa, visa despertar curiosidades sobre este nicho de mercado e fazendo com que futuros empreendedores se sintam incentivados e seguros a adquirirem o mesmo ramo. Já para a população local trará novas opções de entretenimentos e geração de novos empregos, além de proporcionar rapidez no atendimento e usufruir de produtos de alta qualidade. 


\section{Referencial Teórico}

\section{Planejamento Estratégico}

O planejamento estratégico é de suma importância para as organizações, pois são fundamentais para moldar sua postura no mercado em busca dos melhores resultados, é a partir dele que se traçam objetivos e metas que irão determinar o futuro de uma empresa, se serão bem sucedidas ou não, desde modo uma empresa que não possui planejamento estratégico acaba tendo dificuldades de manter atividades e atitudes coerentes, se estabilizando na zona de conforto, e perdendo participações no mercado em decorrência da concorrência. Conforme Drucker (1987), quando a empresa projeta objetivos e metas, e busca alcançá-los, ela tem claramente definido do porque ela existe, o que e como faz, e onde quer chegar.

Segundo Oliveira (2004), os desafios dos novos gestores em meio a globalização tendem a ficar mais acirrados, pois estamos inserido em um mercado que está em constante mudança, tendo que tomar providencias acerca de que o futuro tende a ser diferente do passado, em que o sucesso de uma organização são influenciado pelas ações tomadas no passado, portanto é de suma importância que os gestores se mantenham em constante atualização.

Nesse novo cenário muitos acreditam que para empreender com sucesso basta apenas montar seu próprio negócio sem ao menos ter noção de como geri-lo, fazendo com que muitas vezes cheguem à falência, pois implantar o planejamento estratégico nas organizações torna-se um fator preponderante para sua sobrevivência.

De acordo Kotler (2000), o segredo das empresas bem sucedidas no mercado se deve ao fato de praticarem frequentemente a arte do planejamento estratégico. Com isso fica evidente o quanto o planejamento estratégico deve estar presente dentro das organizações.

\section{Empreendedorismo}

Em meado do século XXI vivencia-se uma era marcada pelas diversas modificações em curto período de tempo, uma delas que foi bastante relevante é incentivo do empreendedorismo, visto como uma arte de transformar ideias em grandes oportunidades de negócios, que cada vez mais vem crescendo. 
Segundo Dornelas (2008), empreendedorismo é o envolvimento de pessoas e processos que em conjunto, levam à transformação de ideias em oportunidades. E a perfeita implementação destas oportunidades leva à criação de negócios de sucesso. Há cada vez mais políticas de incentivo estão surgindo, para revitalizar o espírito empreendedor, como por exemplo, a criação do microempreendedor individual (MEI).

Segundo a Lei complementar $n^{\circ} 123 / 06$, define o conceito de Microempreendedor Individual (MEI) em seu art. 18-A da seguinte forma:

§ 1o Para os efeitos desta Lei Complementar, considera-se MEI o empresário individual a que se refere o art. 966 da Lei no 10.406, de 10 de janeiro de 2002 (Código Civil), que tenha auferido receita bruta, no ano-calendário anterior, de até R\$ $60.000,00$ (sessenta mil reais), optante pelo Simples Nacional e que não esteja impedido de optar pela sistemática prevista neste artigo.

Já para Pessoa (2003), caracteriza o empreendedorismo como as atividades desenvolvidas por uma pessoa ou grupo delas com o propósito de chegar à realização de empreendimento ou negócio partindo de um objetivo. Sendo assim fica claro que o empreendedorismo sempre tem um determinado foco.

\section{Segmentos de Choperia}

O consumidor brasileiro tornou-se um grande apreciador de cerveja, fazendo com que o Brasil se consagre um dos maiores produtores de cerveja do mundo, e este cenário a cada dia vem passando por diversas mudanças, e que está atrelado diretamente com o consumidor, pois estamos vivenciando uma nova era que exige cada vez mais dos seus fornecedores, que para isso precisa está frequentemente praticando o ato de novas técnicas e conhecimentos, a fim de buscar entender melhor e suprir a necessidade do seu público alvo, outro aspecto de total importância para as organizações deste segmento, é esta atentos ao que o mercado está exigindo, realizar análises que venham a contribuir na tomada de decisão. Vale ressaltar que investir no quesito qualidade pode se tornar uma vantagem diante os concorrentes.

Quando os resultados obtidos são transformados em grandes estratégias para alavancar os lucros e o número de clientes. Para que o empreendedor possa estar apto as mudanças, é

245 Id on Line Rev. Mult. Psic. V.12, N. 42, Supl. 1, p. 242-254, 2018 - ISSN 1981-1179 Edição eletrônica em http://idonline.emnuvens.com.br/id 
essencial que o mesmo adote novos conhecimentos com frequência, tenha uma visão diferenciada dos demais e se tornem bem flexíveis, e praticando com frequência o ato de inovar.

Para Drucker (1986), os empreendedores usam a inovação como instrumento específico para explorar a mudança como uma oportunidade, um novo negócio ou um novo serviço. Com isso deixa-se evidente o quanto inovar é primordial para que as organizações se mantenham no topo do mercado, além de proporcionar novas oportunidades que venham a elevar a participação e referência, causando destaque diante os concorrentes.

\section{Qualidades no Atendimento}

Segundo Kotler e Armstrong (2003), atrair e reter clientes podem ser uma tarefa difícil. Hoje, os clientes têm à sua disposição uma grande variedade de escolha de produtos e marcas, preços e fornecedores. Diante isto quando se fala em qualidade no atendimento ao cliente, devese atentar bastante a todos os aspectos, desde o primeiro contato até o contato final, pois quando o cliente se sente valorizado e recebe um bom atendimento, passa a analisar a empresa como uma das melhores do seu segmento, vale ressaltar que suprir as expectativas do consumidor é um papel preponderante para alavancar a lucratividade da empresa, o que se torna essencial para o sucesso da organização, além de elevar seu status e proporcionar mais vantagens com relação à concorrência.

As empresas que quiserem continuar no páreo, e apresentando lucros, terão que adotar a Gestão da Qualidade Total, que justamente seria se posicionar um passo à frente diante a concorrência de um mercado tão competitivo, que se vivencia uma era que segue altos padrões de qualidade, em que cada vez mais se exige qualificações dos gestores para que os tornem mais flexíveis e passem a ter uma visão mais holística. Com isso pode-se dizer que é inevitável se especializar, a fim de trazerem melhorias e benefícios para as organizações (KOTLER, 2000).

A choppertainer visa o cliente como foco principal para o crescimento do estabelecimento e por estes motivos da ênfase na qualidade e praticidade no atendimento, com intuído de ganha a fidelidade do cliente e se tornar uma das maiores choperias da região, se

246 Id on Line Rev. Mult. Psic. V.12, N. 42, Supl. 1, p. 242-254, 2018 - ISSN 1981-1179 Edição eletrônica em http://idonline.emnuvens.com.br/id 
sobressaindo diante dos concorrentes pela eficiência e eficácia, dos produtos e serviços oferecidos.

\section{Metodologia}

Através desta pesquisa, será realizado um estudo de caso nos setores de bares, oferecendo mais entretenimento para a sociedade, entretanto foram realizadas pesquisas com abordagens quali-quantitativa, onde as duas são divergentes para que o cruzamento de dados seja maior, fazendo com que o valor da pesquisa também cresça. Vale ressaltar que a pesquisa é básica e tem caráter exploratório, uma vez que tem como objetivo familiarizar-se com um assunto ainda pouco conhecido, ou pouco explorado (GIL, 2008).

A cidade de Brejo Santo-CE, que possui a população de 45193 mil pessoas, de acordo com o último censo do IBGE. A pesquisa acontecerá no bairro Aldeota da cidade referida acima, entre jovens e adultos acima de 18 anos, onde serão aplicados questionários, e em seguida serão realizados a coleta de dados e posteriormente inseridos em uma planilha Microsoft Excel 2010.

Os resultados obtidos servirão como parâmetro para tornar o empreendimento diversificado. Além de oferecer serviços com atendimento qualificado, padronização do estabelecimento e produtos da mais alta qualidade posta no mercado. Com o intuito de causar boa repercussão e destaque entre as demais organizações, e consequentemente despertando nos empreendedores a curiosidade e o desejo de estar à frente de um negócio viável.

\section{Análise e Interpretação de Dados}

Ao analisar a população da cidade de Brejo Santo-CE, constatou-se que a melhor localidade a ser implementada choppertainer foi o no bairro Aldeota, pois é visto como uma referencia para as pessoas que buscam por entretenimento, com isso definimos a população de amostragem através de um calculo amostral, com um índice de $99 \%$ da população com faixa etária de 18 anos acima de classe A a C. Através de questionários buscou-se identificar as características do público-alvo, como gênero faixa etária, renda entre outros. 


\section{Gráfico 01: Gênero.}

Masculino Feminino

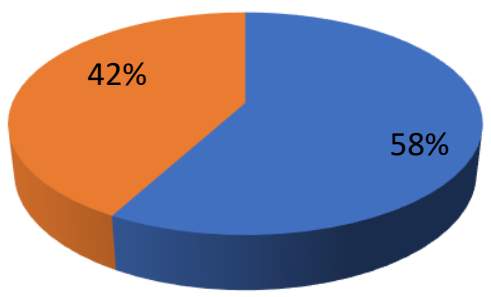

Fonte: Dados da Pesquisa 2018.

O gráfico 01 nos mostra em parcelas referentes aos gêneros masculinos e femininos que de um total de 354, foram 205 masculino, que representa em porcentagem 58\% e 149 feminino referente a $42 \%$ da população alcançada.

Gráfico 02: Faixa Etária.
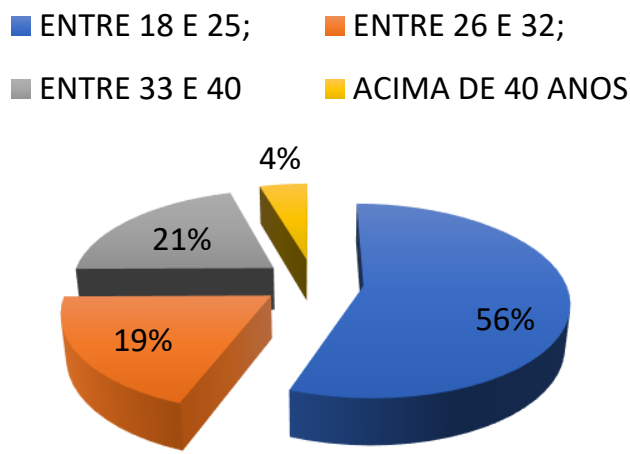

Fonte: Dados da Pesquisa 2018.

Com base no gráfico 02, percebe-se que o maior percentual atingido é entre 18 e 25 anos totalizando um percentual de 56\% equivalente a 197 pessoas, tendo em vista que este é um ponto positivo, pois o publico mais jovens costuma sair à noite na cidade, a fim de entretenimento, já entre 26 e 32 equivale a $19 \%$ referente a 68 pessoas respondentes, entre 33 e 40 nota-se que equivale a $21 \%$ totalizando 73 pessoas e por fim acima de 40 anos equivale a $4 \%$ sendo 16 pessoas respondentes. 
Gráfico 03: Costuma Sair a Noite na Cidade de Brejo Santo-CE.

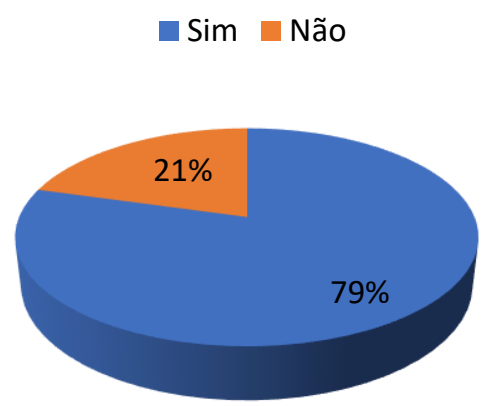

Fonte: Dados da Pesquisa 2018.

O gráfico 03 revela se a população costuma sair a noite na cidade de Brejo Santo CE, e os resultados obtidos mostram que $79 \%$ dos respondentes costumam sair a noite e $34 \%$ responderam que não.

Gráfico 04: Frequência que Costuma Sair a Noite.

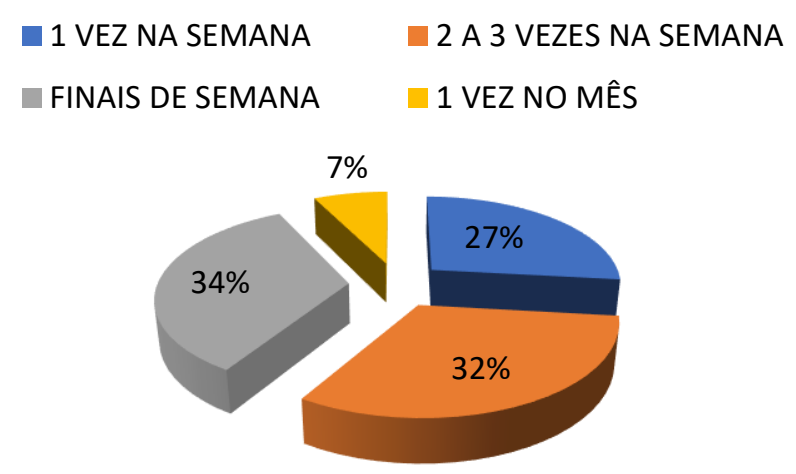

Fonte: Dados da Pesquisa 2018.

Conforme o gráfico 04 nota-se que 34\% que equivale a um total de 110 respondentes saem mais nos finais de semanas, deixando evidente que representa os principais dias de maior movimentação que o estabelecimento poderá receber, já 2 a 3 vezes na semana equivale a 32\%, referente a 104 respondentes, 01 vez na semana representa graficamente a $27 \%$ totalizando 89 respondentes e 01 vez no mês representa $7 \%$ equivalente 24 respondentes. 
Gráfico 05: Já Tomou Chopp.

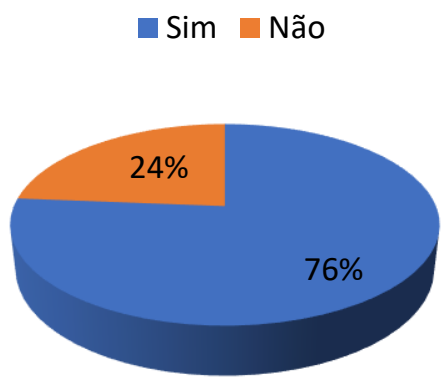

Fonte: Dados da Pesquisa 2018.

De acordo com os resultados obtidos no gráfico $05,76 \%$ dos respondentes já tomaram chopp e $24 \%$ não, para saber se estes resultados são satisfatórios para o estabelecimento, foi elaborada a pergunta, “tem interesse em tomar?”. As respostas estão expressas no gráfico 06.

Gráfico 06: Tem Interesse em Tomar Chopp.

- Sim não

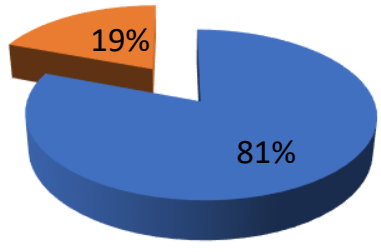

Fonte: Dados da Pesquisa 2018.

Conforme o resultado obtido, pode notar-se que de certa forma é um ponto positivo para o estabelecimento, pois $81 \%$ dos respondentes que não havia tomado chopp até o momento tem o interesse em provar da bebida, e apenas $19 \%$ não possui interesse. 
Gráfico 07: Renda Mensal.

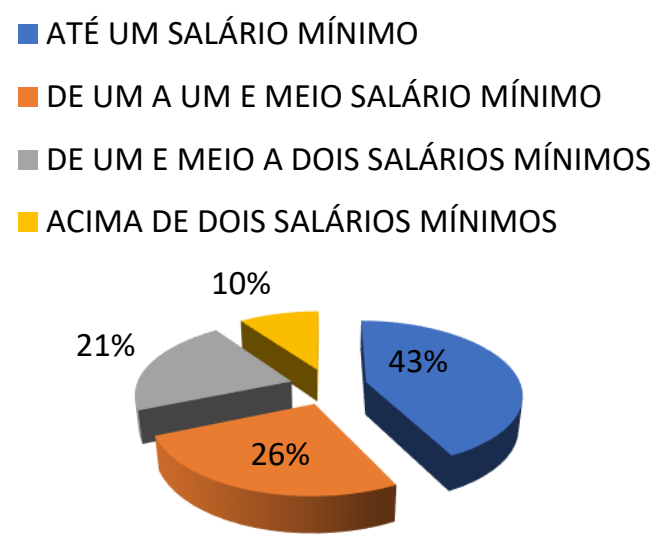

Fonte: Dados da Pesquisa 2018.

Como apresentado graficamente, nota-se que a maior renda equivale a um salário mínimo representando $43 \%$ dos respondentes o que torna um risco para o empreendimento, de um a um e meio salário mínimo representa $26 \%$ de um e meio a dois salários representam $21 \%$ e $10 \%$ dos respondentes recebem acima de dois salários mínimos.

Gráfico 08: Custo Médio que Costuma Gastar ao Sair para uma Choperia.
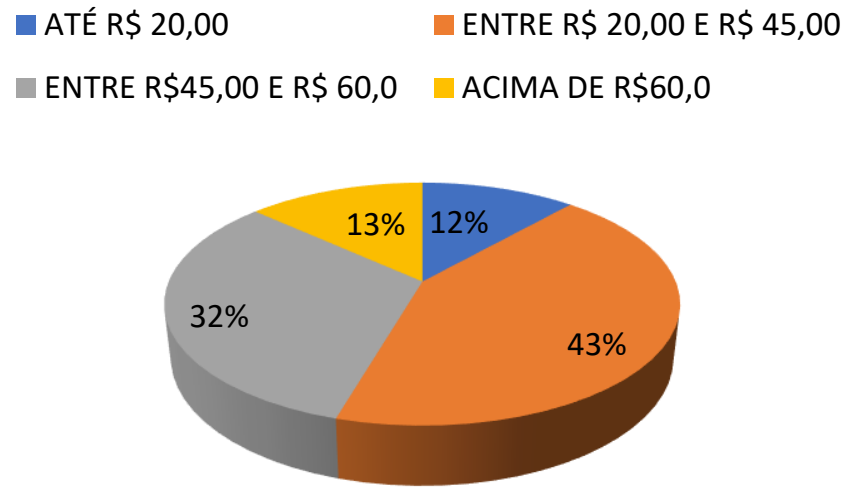

Fonte: Dados da Pesquisa 2018

Conforme os dados obtidos no gráfico 08 , percebe-se que $12 \%$ optam por gastar até 20 reais quando saem para uma choperia, o que representa um risco para o estabelecimento, já $43 \%$ 
costumam gastar entre 20 e 45 reais, e $32 \%$ gastam entre 45 a 60 reais, e $13 \%$ acima de 60 reais.

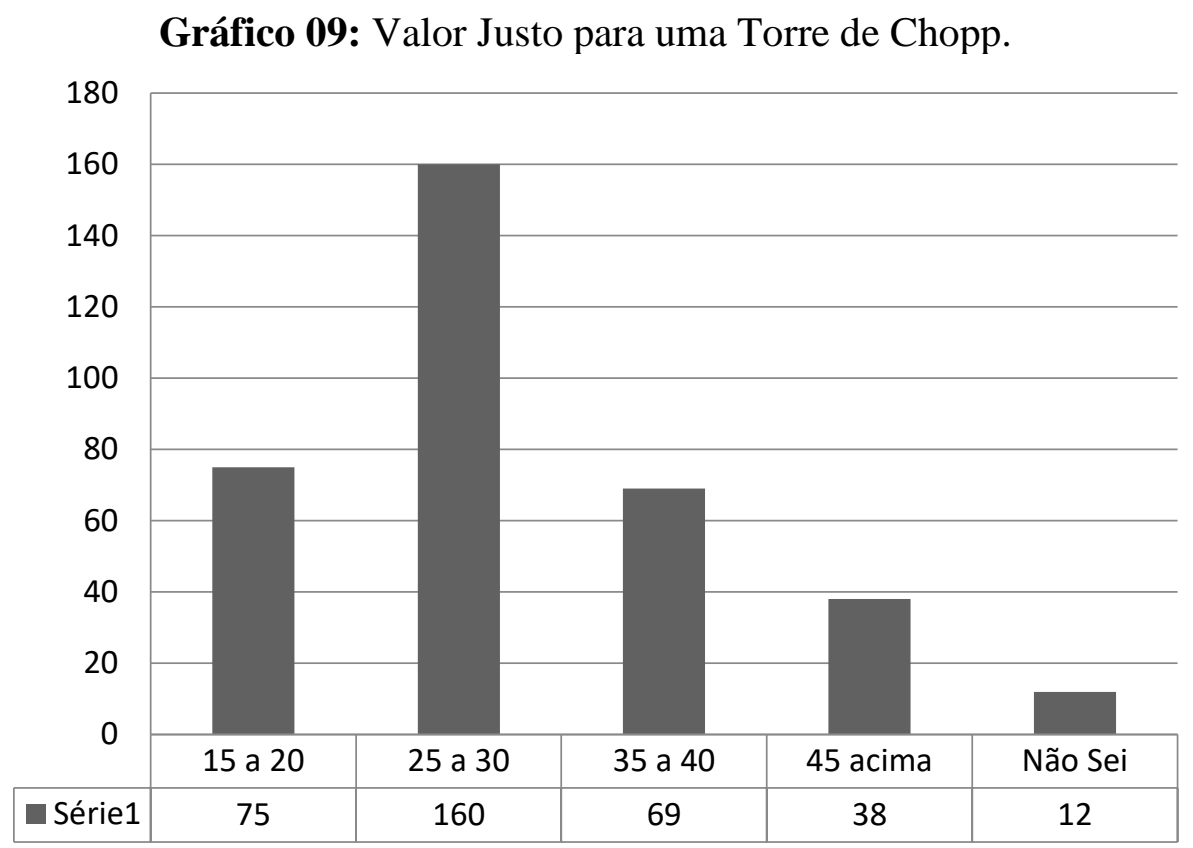

Fonte: Dados da Pesquisa 2018.

De acordo com os dados representados no gráfico 09 , pode-se analisar que o preço justo considerado por $45 \%$ dos respondentes foi de $\mathrm{R} \$ 25,00$ a $\mathrm{R} \$ 30,00$.

Gráfico 10: Meios de Informações para Saber de Promoções.

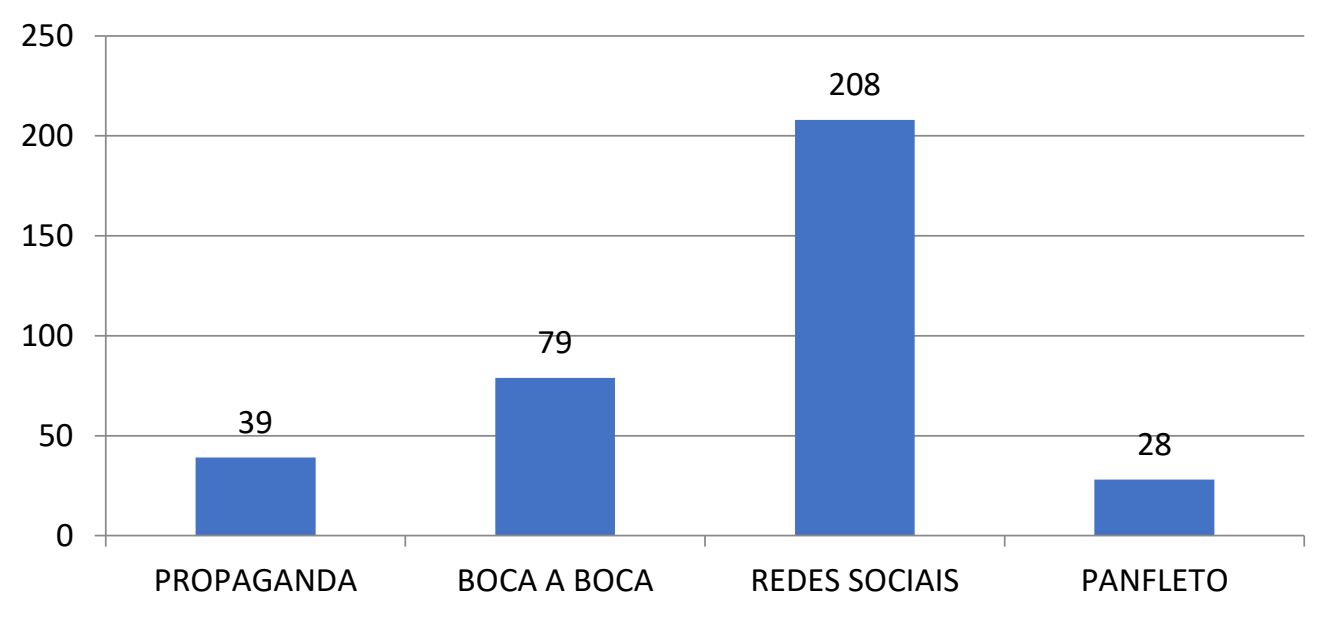

Fonte: Dados da Pesquisa 2018. 
As redes sociais atualmente estão se transformando em uma das maiores influências, evidenciada no gráfico 10 , que mostra $59 \%$ dos respondentes optaram pela opção de redes sociais para saberem de promoções.

\section{Considerações Finais}

Levando em consideração os resultados obtidos com a pesquisa, a viabilidade desta proposta de negócio, mostra-se favorável para implantação.

A finalidade principal do estudo foi analisar os aspectos relevantes para sentenciar a viabilidade de implantação de uma choperia na cidade de Brejo Santo-CE. Com base na pesquisa a maior parte dos participantes possui renda de até um salário mínimo e gastam em média numa choperia 20 a 45 reais. E estão dispostos a pagar por uma torre de Chopp entre 25 a 30 reais.

O público entrevistado possui vida social ativa, julgando o costume de sair mais de uma vez à noite, na cidade referida. É notório também com os resultados da pesquisa que os futuros clientes já tomaram e tomariam Chopp. Vale destacar que a maioria dos participantes pontua o interesse em propagandas pelas redes sócias.

O mercado está cada vez mais competitivo, por isto quem deseja empreender, deve iniciar um negócio de forma diferente e eficaz. Por intermédio do planejamento estratégico há uma possibilidade de preparo para a entrada no mercado, sendo possível efetivar a viabilidade de um empreendimento. A qualidade no atendimento é um quesito desejável pelos clientes, deste modo ao implantar um negócio, a qualidade deve ser primordial para satisfazer e fidelizar clientes.

Com os resultados deste estudo de viabilidade, fica aberto para futuros pesquisadores o desenvolvimento de um planejamento estratégico que vise à implantação de uma choperia na cidade de Brejo Santo-CE. 


\section{Referências}

BRASIL. Lei complementar $n^{\circ} 123 / 2006$, DE 31 DE MARÇO DE 2006. Lei geral da micro e pequena empresa, Brasília, disponível em: https://centraldomei.com/lc-1232006-lei-geral-da-micro-e-pequenaempresa/. Acesso em: 24 de ago. 2018.

CHIAVENATO, Idalberto. Empreendedorismo: dando asas ao espírito empreendedor. São Paulo: Saraiva, 2005.

Empreendedorismo: dando asas ao espírito empreendedor: empreendedorismo e viabilidade de novas. 2. ed. rev. e atual. São Paulo: Saraiva, 2007.

DORNELAS, José Carlos Assis. Empreendedorismo: transformando ideias em negócios. Rio de Janeiro: Elsevier, 2008.

DRUKER, Peter Ferdinand. Inovação e espírito empreendedor. Editora Pioneira, 1987.

GIL, Antonio Carlos. Como elaborar projetos de pesquisa. 5. ed. São Paulo: Atlas, 2008.

KOTLER, Philip e ARMSTRONG, Gary. Princípios de Marketing. 9. ed. São Paulo: Prentice Hall, 2003.

Administração de marketing. 10. ed. São Paulo: Prentice Hall, 2000.

Administração de Marketing. 12. ed. São Paulo: Prentice Hall, 2000.

LUECKE, Richard. Ferramentas para empreendedores. Rio de Janeiro: Record, 2007.

OLIVEIRA, Djalma de Pinho Rebouças. Planejamento Estratégico: conceitos, metodologias e práticas. 13. ed. São Paulo: Atlas, 2004.

PESSOA, Sylvio. Gerenciamento de empreendimentos. Florianópolis: Insular, 2003.

SEBRAE. Como elaborar um plano de negócio. 2009, Disponível em <http://www.sebrae.com.br/sites/PortalSebrae>. Acesso em 27 de ago. 2018.

BESSANT, John; TID, Joe. Inovação e Empreendedorismo. Trad. Elizamari Rodrigues Becker, Gabriela Perizzolo, Patrícia Lessa Flores da Cunha. Porto Alegre: Bookman, 2009.

CHURCHILL, Gilbert A.; PETER, J. Paul . Marketing: Criando valor para os clientes. Tradução da $2 \mathrm{a}$. ed. São Paulo: Saraiva, 2005.

\section{Como citar este artigo (Formato ABNT):}

TELES, Leticia Ricarte; FERREIRA, Thalia Lourdes; COSTA NETO, Manoel Leal; OLIVEIRA, Alyne Leite de; ALENCAR, Tharsis Cidália de Sá Barreto Diaz. Verificação de Interesse para a Implantação de uma Cafeteria na Cidade de Brejo Santo-CE. Id on Line Rev.Mult. Psic., 2018, vol.12, n.42, Supl. 1, p. 242-254. ISSN: 1981-1179.

Recebido: 06/11/2018;

Aceito: 07/11/2018. 